Review Article

\title{
Psychoeducational Interventions for Family Caregivers of Seniors across Their Life Trajectory: An Evidence-Based Research Program to Inform Clinical Practice
}

\author{
Francine Ducharme $e^{1,2}$ \\ ${ }^{1}$ Faculté des sciences infirmières, Université de Montréal, C.P. 6128, Succursale Centre-ville, Montréal, QC, Canada H3C 3J7 \\ ${ }^{2}$ Centre de Recherche, Institut universitaire de gériatrie de Montréal, 4565 Queen Mary, Montréal, QC, Canada H3W 1W5 \\ Correspondence should be addressed to Francine Ducharme; francine.ducharme@umontreal.ca
}

Received 27 February 2014; Accepted 30 May 2014; Published 19 June 2014

Academic Editor: Kiminobu Sugaya

Copyright (C) 2014 Francine Ducharme. This is an open access article distributed under the Creative Commons Attribution License, which permits unrestricted use, distribution, and reproduction in any medium, provided the original work is properly cited.

\begin{abstract}
Family caregivers of the elderly are growing in number and the care they are called upon to deliver in industrialized countries is becoming increasingly demanding and complex. Empirical research shows that the caregiving situation can have a significant impact on the health of these caregivers often on account of stress, physical and psychological exhaustion, and a sense of being overwhelmed. In this context, the quality of life of these caregivers depends in large part on professional educational and support interventions. The purpose of this paper is to present three innovative psychoeducational intervention programs developed and empirically tested by the research team of the Université de Montréal's (Québec, Canada) Chair in Nursing Care for Seniors and Their Families over the past fifteen years. These interventions have been developed together with family caregivers experiencing different stressful situations across their care trajectory. The results of evaluative studies of these programs provide evidence to inform professional clinical practice. Future directions for caregiving research are discussed.
\end{abstract}

\section{Introduction}

Family caregivers of the elderly are growing in number in North America, as in all industrialized countries, and the care they are called upon to deliver is becoming more complex. Research shows that caregiving can have a significant impact on their health. Indeed, caregiver health is often undermined by stress, physical and psychological exhaustion, and a sense of being overwhelmed-all ailments generated by the responsibilities of caring for their aging relatives $[1,2]$. As a result, family caregivers are increasingly considered an at-risk clientele within the healthcare system and their quality of life (QoL) has come to depend on professional support in the form of educational interventions, counselling, and respite services.

In response to the situation, numerous initiatives have been developed in the past few decades to help family caregivers. However, the results of evaluative research, systematic literature reviews, and meta-analyses regarding these initiatives have, in general, proved inconclusive [3-10]. In fact, the interventions and services developed have had modest effects at best and do not seem to have a significant influence on caregiver health and QoL.

Among the reasons put forth to explain these conclusions, it appears above all that the elements of the proposed interventions are not specific enough to meet the particular needs of caregivers at the different stages of their trajectory. This trajectory often spans numerous years, from the moment of diagnostic disclosure to the period of grieving the loss of one's elderly relative [11], and the needs of family caregivers evolve along the way. For example, caregivers need to know what to expect after being notified of their relative's diagnosis, especially with respect to the services that will be available to support them. Later on in their trajectory, they will need to acquire strategies for better managing the stressful situations related to the daily care of their elderly relative and to learn to ask for required help from their social support network. Finally, if placement becomes necessary, the need to learn 
how to communicate with institutional personnel and to gain a better understanding of the relative's new life environment must be taken into account as well.

It was therefore with an eye on the necessity of interventions tailored to the needs of family caregivers across their care trajectory that the studies that we conducted over the past 15 years focused on the development, testing, and empirical evaluation of psychoeducational support programs for family caregivers of elderly persons with declining physical or cognitive functioning. This paper presents three of these programs that have been the subject of rigorous evaluative studies and that have demonstrated significant effects on different dimensions of caregiver health and QoL, namely, (1) an individual program titled learning to become a caregiver for preparing a smooth transition towards the family caregiver role following diagnostic disclosure of dementia or a related disease in an elderly relative [12]; (2) a program for learning how to manage stress intended for in-home caregivers and offered in two modes, namely, via individual sessions at home with a health professional or via sessions on the web assisted by a professional who plays the role of "online coach" [13]; and (3) a group program titled taking care of myself for caregivers who have placed a relative with dementia in a long-stay care facility [14].

Rigorously developed and evaluated over the past decade, these programs afford concrete avenues of intervention to clinicians who work with this growing clientele of caregivers. This paper provides a synthesis of the content and theoretical framework of these programs, the methodology selected for their empirical evaluation, and their principal significant effects on caregiver health and QoL. The aim of grouping these data in one and the same paper is to present practitioners wishing to engage in an evidence-based practice with an array of interventions that can be delivered in different modes and that take account of where the caregiver is situated along the caregiving trajectory. Closing the paper is a discussion of the significance of this research work and of the recommendations for future studies in the field of caregiving. Readers interested in learning more about the specifics of the methodology used can do so by consulting the original earlier articles published elsewhere.

\section{Preparing for the Role of Family Caregiver: The Learning to Become a Family Caregiver Program}

2.1. Background of Study. A large number of family caregivers are expected in the near future to set upon a long trajectory of caring for a relative with Alzheimer's disease. Intervention programs have been designed primarily for persons with extensive caregiving experience and, as previously mentioned, the effects of these programs on QoL are quite modest [15]. Although methodological limitations can explain the results obtained with these programs, the content of interventions might not be specific enough or tailored to meet caregiver needs across the stages of the caregiving career. Interventions offered at particular points in time are more likely to be effective than those provided without consideration of the caregiver's own care trajectory $[10,16]$. Moreover, intervention programs appear to be offered in an untimely fashion. In this regard, more and more authors recommend taking a proactive approach, that is, offering early intervention at the outset of the care trajectory, rather than a reactive approach, as is the case with most programs (see [17]).

There are many reasons to be concerned with family caregivers early in the care trajectory and, more specifically, in the period following diagnostic disclosure of the relative's dementia. Diagnostic disclosure marks the official entry into the caregiver career and confirms the irreversibility of the illness [18, 19]. Family caregivers are then inevitably confronted with a change in family roles and responsibilities. They must learn to cope with the many behavioural changes associated with the disease and to plan for the future [19-21]. The diagnostic disclosure period, referred to as the encounter stage by Lindgren [22] and the confirming stage by Keady and Nolan [19], is considered to be a key marker of the caregiver career, characterized by an urgent need to acquire new knowledge related to becoming a caregiver [19]. Yet, despite the necessity of preparing to cope with the transition to the caregiver role, few studies have focused on family caregivers at this particular moment in their trajectory.

Against this backdrop and from a proactive perspective, we undertook to develop and evaluate a psychoeducational intervention program sensitive to family caregiver needs following diagnostic disclosure of a relative's Alzheimer's disease (for more details see [23-25]).

2.2. Theoretical Framework. We selected a theoretical framework suited to the phenomenon of family caregiver role acquisition, namely, the role transition model developed by Meleis and colleagues [26]. According to this theoretical model, a transition constitutes a period of instability accompanied by uncertainty. It represents the passage from one state or condition to another. Transitions are associated with life development stages or with specific situations, such as the passage towards new roles, including that of family caregiver. A successful role transition is characterized by the acquisition of new knowledge and skills, perceived self-efficacy in the face of the caregiving situation, and satisfactory relations with the social support networks, both formal (services) and informal (family and friends).

Given the importance of considering family caregivers as partners [16], we chose to develop the intervention following a participatory and constructivist model [27]. Accordingly, we considered family caregivers as experts and principal stakeholders in the project using an adapted version of the intervention mapping model [28]. More precisely, we undertook a large longitudinal study comprising five steps (1) exploring family caregiver needs; (2) developing and validating an intervention program proposal together with caregivers; (3) formalizing program through intervention mapping; (4) testing and qualitatively evaluating formalized program; and (5) testing program effects on selected health and QoL outcomes quantitatively. These steps are summarized in the following sections. 
2.3. Step 1: Explore Family Caregiver Needs. The necessity of exploring family caregiver needs arose from the fact that very little data existed regarding the official passage to the caregiver role and that such data were essential to developing tailored intervention programs [29-31]. Family caregivers were recruited with the help of cognition clinics in two urban regions of Quebec (Canada). Caregivers had to meet the following selection criteria: being self-defined as the primary family caregiver of a relative (spouse or parent) aged 65 years or older; diagnostic disclosure of relative's probable Alzheimer's disease or other related disorder received in the past nine months; and not benefiting from any individual psychotherapy, family therapy, or support group during the study. The number of participants $(n=13)$ was determined by data saturation. Family caregivers (four wives, three husbands, five daughters, and one son) had a mean age of 67 years and had been informed of the diagnosis two months earlier on average. The cared-for relatives had a mean age of 80 years.

In order to explore family caregiver needs in depth, we conducted semistructured interviews. Various questions regarding the phenomenon of caregiver role transition [26] were asked (e.g., communicating with a family member who suffers from Alzheimer's disease can be challenging and frustrating. Have you experienced any changes in this regard? What type of information or training would you need in order to take better care of your relative?). Based on a content analysis, the needs expressed by the participants interviewed were the following: (1) understanding their relative's illness; (2) developing new skills adapting to their relative's present situation and striking a balance between family and personal life; (3) developing communication skills to interact with their relative; (4) receiving reassurance about their caregiving capacity and giving a meaning to their caregiver role; (5) discussing responsibility for care among family members; (6) becoming familiar with services available within the formal support network and creating ties with healthcare professionals; and (7) knowing what to expect regarding their ill relative and themselves and planning for the future.

2.4. Step 2: Develop and Validate a Program Proposal. The second step consisted in developing a program proposal based on the needs identified and validating it with family caregivers. The program that emerged was a psychoeducational intervention that covered themes concerning the skills required to meet the expressed needs. The aim was to ensure a close match or fit between these needs and the intervention strategies chosen to foster a successful transition to the caregiver role. The intended objectives specific to each theme were then defined and a general outline of the content to be proposed to caregivers was developed. The preliminary program comprised seven individual weekly sessions. Examples of themes included "learning to live with the certainties and uncertainties of the illness" and "using one's strengths in caring for the relative."

Under the participatory approach, it was imperative that the family caregivers validate the program proposal in order to ensure that the content met their needs and expectations
$[28,32]$. The 13 caregivers who took part in the first step of the study were recontacted to participate in the validation process. They were then invited to a workshop, which served to set a reflexive process in motion [33].

The workshops consisted of a discussion centred primarily on the relevance and clarity of each of the themes, as well as on their objectives, the type of activities to be proposed, and the number and frequency of sessions. Questions asked included the following. If you look at your situation, does this theme properly reflect your needs as a family caregiver who has just learned his/her relative's diagnosis? Are there themes that should be added, eliminated, or modified? How do you see this program being offered in the form of discussions with a health professional or through written documents with exercises to be completed at home? (A help-seeking exercise was presented as an example.)

2.5. Step 3: Formalize Program. We then undertook formalization, which consisted of operationalizing the program proposal through intervention mapping [28]. In accordance with this approach, we ensured that the objectives related to each of the themes were formulated in terms of targets that specified the knowledge and skills that needed to be acquired by family caregivers in order to meet their needs and to facilitate their adaptation to the caregiver role. These performance targets constituted indicators of a successful role transition, the program's intended effect. Moreover, we specified the content that had to be covered in order to achieve the performance targets, based not only on the general theoretical model of role transition [26], but also on middle-range theories and empirical works, as stipulated by this approach. For example, the content of the theme "learning to live with the certainties and uncertainties of the illness" was based on the illness beliefs model [34]. According to this model, caregivers have beliefs regarding Alzheimer's disease (e.g., causes, course, and treatment), as they do about their caregiver role and that of their family members and of health professionals. These beliefs colour their perceptions and steer their actions following diagnostic disclosure. Another example concerns the theme pertaining to the use of one's strengths in caring for the relative. Bandura's social cognitive and self-efficacy theory $[35,36]$ served to underpin the content of this session. Under this theory, caregivers with a high level of self-efficacy possess the confidence to exercise control over the demands of their environment, which contributes to counter their healthrelated vulnerability [37].

Finally, two workbooks were developed, one for the program leader (health care professional) and the other for the caregivers. The latter contains documents and exercises to be completed between sessions, which are intended to get the family caregivers to put into practice the intervention strategies discussed during each session.

The program titled learning to become a caregiver is outlined in Table 1. It presents family caregiver needs and corresponding themes, performance targets, main theoretical models and empirical works, and content, as well as examples of exercises to be completed by caregivers. 


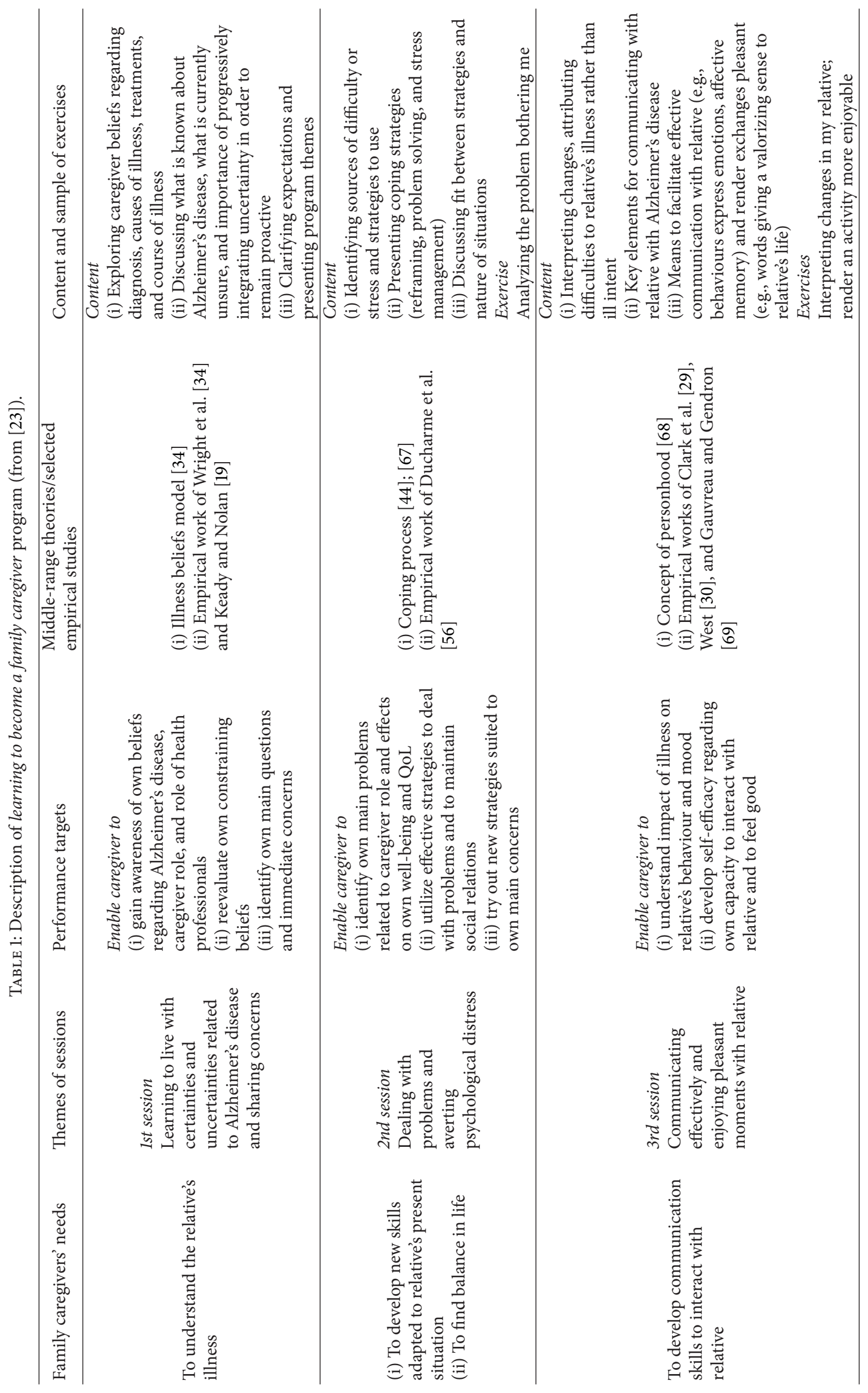




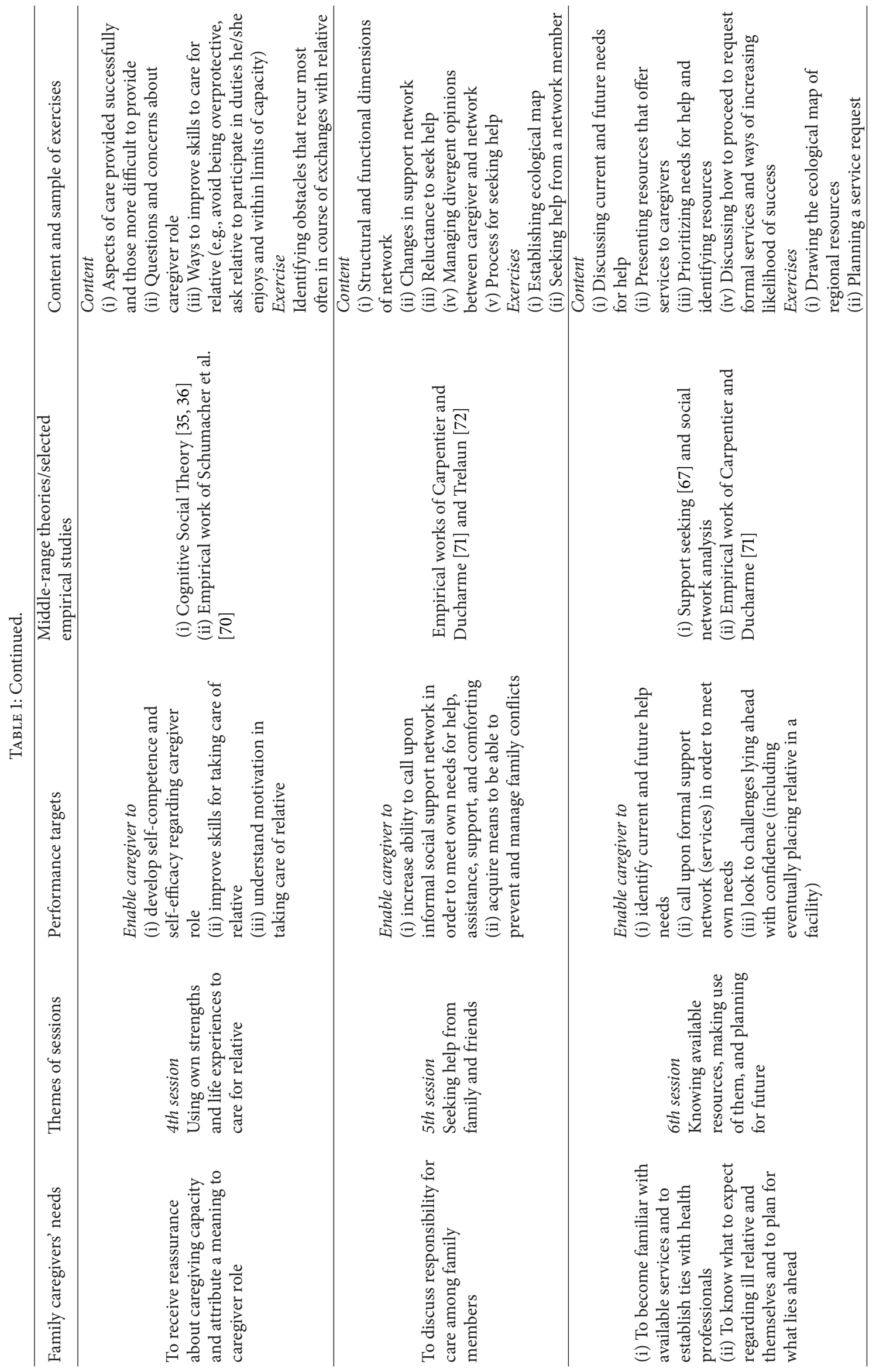




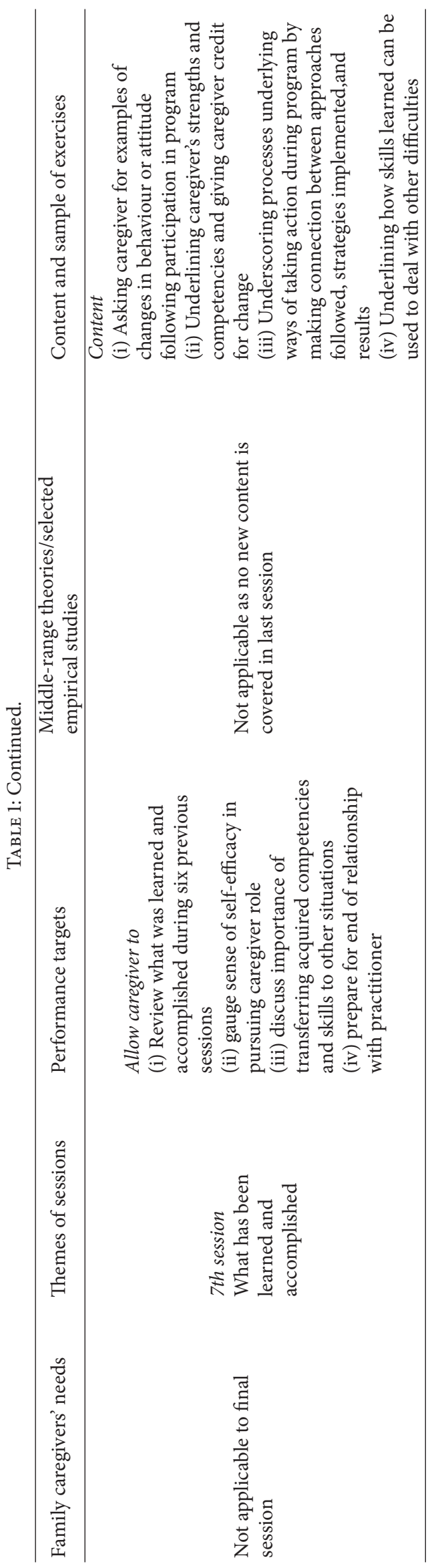


2.6. Step 4: Test and Qualitatively Evaluate Program. Once formalized, the program was tested and qualitatively evaluated with family caregivers in order to document its acceptability and feasibility, as well as the relevance of its various components (see [23]). A semistructured interview grid constructed to this end comprised questions regarding, in particular, the useful and nonuseful aspects of the intervention in terms of content, structure, and process, as well as suggestions on how to improve the program. The family caregivers had to provide concrete examples of perceived changes in their daily life for each of the themes covered. Here are a few examples of the questions asked. How did your way of responding to difficulties change? Tell me about the means or strategies discussed that you put into practice in your daily life. Will these sessions help you feel more competent or efficacious in your life with respect to your relative? Could you give me some examples?

Family caregivers who took part in this individual assessment $(n=6)$ asserted having acquired some learning. They mentioned having learned how to communicate better with their relatives, to care for themselves, and to seek help from extended family and formal services. Here are a few of their statements, drawn from the transcripts, to illustrate the learning gained:

I now pay closer attention to my husband's mood. I have the impression I listen to him better and manage to prevent confrontations that could have escalated for no reason. Also, if I listen to him more, my husband tends to express himself more.

I learned a few tricks to avert escalations when communicating with my father. Now, I just ignore the start of an escalation and it does not go any further.

I learned how to seek help from the members of my family. Before, I would never have dreamt of asking them for anything. Now I do.

2.7. Step 5: Test Program Effects on Selected Health and QoL Outcomes Quantitatively. To test the efficacy of the program, we used a multisite randomized controlled design. Caregivers were recruited in memory clinics and randomized to an experimental group $(n=62)$ or a control group $(n=49)$ receiving usual care. Eligible participants-primary caregivers of a relative diagnosed with Alzheimer's disease in the past nine months-were assessed blindly before randomization, at the end of the program (posttest), and three months later (follow-up) on different outcomes associated with healthy role transition: confidence dealing with caregiving responsibilities and tasks, preparedness to provide care, self-efficacy in caregiver role, planning for relative's future care needs, knowledge of available services, coping, perceived support from informal social network, and fewer family conflicts. These outcomes were measured using standardized instruments with sound psychometric properties (for details, see [24]). Several significant differences emerged from the analyses of covariance results between the experimental group (EG) and the control group (CG). Compared with their CG counterparts, EG caregivers reported greater confidence dealing with caregiving situations, felt better prepared to provide care, and showed greater self-efficacy upon program completion and three months later. These differences explained $8 \%, 22 \%$, and $4 \%$ of the variance, respectively, as gauged by the eta-squared value. Upon program completion and at three-month follow-up, EG caregivers also demonstrated better planning for future care needs of relative and had better knowledge of available services than did CG caregivers. The variance explained by these effects was $4 \%$ and $21 \%$, respectively. Where coping is concerned, EG caregivers made greater use of problem-solving and reframing strategies than did their CG counterparts (resp., 5\% and 7\% of the explained variance). The program had no significant effect on use of stress-management coping strategies, perceived informal support, and family conflicts (see [24], for details on methods).

Following participation in the program, caregivers were offered a 90-minute booster session, a means of maintaining the benefits of psychoeducational programs which has received little attention in caregiving research. The session served to review program content and afforded the opportunity to discuss and practise learned skills. To test the session's efficacy maintaining or recovering program effects six months postprogram [25], participants in the program were randomly assigned to a group that received the booster session $(n=31)$ or a group that did not $(n=29)$. A third control group $(n=29)$ was also formed, which continued to receive only the usual care provided in memory clinics.

We next performed prediction analyses on the data $[38,39]$. Results showed that the booster session had one significant positive effect on emergence of preparedness to provide care. Indeed, at the six-month follow-up assessment, a higher proportion of caregivers in the EG with booster session (55\%) had successful outcomes regarding this variable compared with those in the EG without booster session (41\%) and those in the CG (28\%). When the EG with booster session and the CG were compared, the del value of .27 indicated that the predicted model of an association between booster session and emergence of preparedness described the data $27 \%$ better than did the model of no association $(z=2.19, p=$ $.014)$. In the case of the EG without booster session versus the CG, instead, the del value was low (.14) with a $z$ value of 1.06 that did not prove significant $(p=.144)$. These results lend support to the hypothesis that without a booster session preparedness would not emerge.

EG caregivers with and without a booster session continued to maintain low psychological distress levels at the six-month booster session follow-up assessment. A higher proportion of caregivers in both of these groups than in the CG obtained successful outcomes: $48 \%$ in the EG with booster session, 55\% in the EG without booster session, and $28 \%$ in the CG. According to these results, the learning to become a family caregiver program alone seemed sufficient to maintain low psychological distress. Finally, concerning emergence of self-efficacy, a higher proportion of caregivers in the EG with booster session and in the EG without booster session had successful outcomes (resp., 54\% and 
$45 \%)$, compared with those in the CG (22\%). The del values also supported an association between the EGs with and without a booster session and self-efficacy. For all other outcomes, no significant result was observed in either condition (EG with or without booster session) regarding expected maintenance of effects (knowledge of services, planning for future, reframing) or emergence of effects (social support and family conflicts).

Given that very few caregiving interventions offer booster sessions even though their potential to maintain benefits has been reported for other health intervention programs (see, e.g., [40]), further research is needed in this area.

In conclusion, this longitudinal study yielded data supporting the importance of providing a systematic psychoeducational intervention to family caregivers early in their trajectory. The following section describes an intervention program designed to provide family caregivers who deliver homecare over many years with support to cope with daily stress. This innovative program can be applied in two different modes: as an individual face-to-face intervention and as an e-learning program with an online professional coach. These two modes are described below, as are the results of their empirical evaluation.

\section{Coping at Home with Daily Stressors: A Stress Management Intervention for Family Caregivers}

3.1. Background of Study. In Canada, the United States, and numerous European countries, the home is being increasingly formalized as a care-delivery setting for seniors [41]. Unfortunately, healthcare services have been shortsighted in considering family caregivers as potentially useful resources for the purpose of care delivery rather than as a target clientele. Consequently, services today do not systematically seek to address the health needs of these potential clients.

These caregivers experience anxiety and insecurity over the care that they are called upon to deliver for many years at home. They have difficulty understanding the complexity of the healthcare system, have little training to meet the care requirements of their family members, and perceive services as they are currently organized to be fragmented and poorly integrated [42].

As already mentioned, results of evaluative research concerning the effects of support interventions have not been very conclusive. Among these interventions, however, those geared towards problem solving, social support, or cognitive restructuring have been shown to produce greater effects and a degree of improvement in family caregiver well-being [4]. These findings led us to undertake a project to develop and evaluate the content of a stress management intervention program designed for family caregivers of vulnerable elderly persons living at home [43].

3.2. Theoretical Framework. The stress management program is based on the transactional stress-coping model developed by Lazarus and Folkman [44]. Under this model, which is widely used in caregiving research, family caregivers experience stressful situations when transactions with their environment are deemed to exceed their resources. Family caregivers must therefore learn to cope with these situations. According to the model, the development of efficacious interventions must afford a predominant role to the cognitive appraisal of stressors and resources, to the perception of control, and to coping strategies. These strategies are effective if they fit the type of stressor experienced. For example, the persistent use of a problem-solving method in an unchangeable or uncontrollable situation can exacerbate distress and exhaustion. Similarly, the use of emotion-focused strategies, such as avoidance or wishful thinking, can prove detrimental if they prevent acting on certain elements that are amenable to change.

3.3. Description of Program: Individual Face-to-Face Mode . In accordance with the theoretical framework, the goals of the stress management intervention program are as follows: (1) to modify perceived stress related to situations of home caring for an elderly relative; (2) to improve family caregiver coping with requirements related to the caregiver role; and (3) to promote family caregiver QoL. The program comprises five in-home weekly individual visits of 30 to 45 minutes, as well as a follow-up visit one month later, for a total of six individual meetings with a trained healthcare practitioner. Each visit has specific objectives and learning activities that correspond to the various steps of the stress management process (see Table 2).

First, the family caregiver is solicited to talk about his caregiver experience in general in order to gain awareness of his overall family situation and of the effects of stress on his well-being. Second, the caregiver is guided in selecting a specific stressor on which the stress management process will be oriented. Using the Goal Attainment Scale [45], the caregiver formulates an objective to achieve with a view to lowering the perceived level of the selected stressor. More precisely, this clinical instrument calls on the caregiver to assign a relative importance to the selected stressor and to formulate an objective that is both realistic and appropriate to the situation. Examples of objectives include feeling less guilty when taking time off with other family members and friends, managing to ask the healthcare system for help, and coping better with the aggressive behaviours of the cared-for relative.

Third, the family caregiver analyzes his care situation, in particular by exploring the stressors and the personal, family, and environmental factors that might influence his perception of the selected stressor and his choice of coping strategies normally used. Fourth, together with the caregiver, the practitioner explores different coping strategies (problem solving, reframing, and seeking social support) suited to the selected stressor and the caregiver tries out the most appropriate strategies on the basis of family context and available resources. Fifth, the caregiver and the practitioner examine whether the set objective has been reached, review the process as a whole, and evaluate the new perception of stress. Lastly, the purpose of the follow-up visit is to answer the family caregiver's questions regarding the program and to foster the transfer of learning to other stressful situations. 
TABLE 2: Synthesis of learning steps of stress management process.

\begin{tabular}{ll}
\hline Steps & Content \\
\hline 1 & $\begin{array}{l}\text { Caregiver gains awareness of caregiving situation; identification and analysis of gratifying and irritating } \\
\text { aspects of situation and their effects on own health and QoL. } \\
\text { Choice of a difficulty (stressor) for which caregiver wishes to effect a change; formulation of a concrete } \\
\text { objective to achieve using Goal Attainment Scale [45] } \\
\text { Analysis of context surrounding caregiving situation: personal, family, and environmental factors that } \\
\text { contribute to thoughts and stress, habitual strategies used to manage stress situations } \\
\text { Classification of selected stressor according to whether it is amenable to change or not; gained awareness of } \\
\text { importance of fitting coping strategy (e.g., problem solving, cognitive reframing, and social support seeking) } \\
\text { to stressor; testing of strategy on daily basis } \\
\text { Evaluation of achievement of goal set at start and of perceived stress following stress management process; if } \\
\text { goal not reached, repeat process } \\
\text { Follow-up session: review of overall stress management process; caregiver questions answered; discussion of } \\
\text { potential transferability of process to other difficult situations of daily life }\end{array}$ \\
\end{tabular}

3.4. Program Effects on Selected QoL Indicators. The evaluative study of this stress management intervention followed a mixed research design [43]. Action research was combined with a quasiexperimental study to evaluate its implementation, process, and effects. In all, 96 family caregivers were recruited, of which 81 participated in the three times of measurement (preintervention, postintervention, and three months later). This sample was divided into an experimental group that received the intervention $(n=42)$ and a control group $(n=39)$ that received the usual home visits focused on the health of the vulnerable elderly relative. The intervention was implemented in local community service centers (CLSC) in the province of Quebec (Canada) with the help of practitioners (mostly nurse case managers), the participating family caregivers, and a nurse coach. It was then evaluated blindly by a trained interviewer using standardized instruments included in an interview guide.

Next, analyses of covariance were performed on the quantitative data. Results showed that the intervention had statistically significant effects on selected QoL outcomes. More specifically, EG caregivers perceived greater control over their homecare situation and greater informal support from family and friends. Moreover, they perceived their caregiving situation more as a challenge than a threat. They also made greater use of the coping strategy of problem solving in the face of everyday difficulties. Effect sizes (eta squared) ranged from .09 to .14. Qualitative data demonstrated caregiver empowerment with respect to the caregiving role. Furthermore, most family caregivers (74\%) managed to achieve their initial objective relative to the stressor that they had selected. Among these caregivers, 79\% exceeded their initial objective (for more details on the methodology, see [43]).

3.5. E-Learning Mode. The evaluative work on the face-toface stress management program opened up concrete avenues for intervention with families caring for a vulnerable member at home. However, one problem that remained was that many caregivers in isolated locations had difficulty gaining access to services. Consequently, we redesigned the psychoeducational program to take advantage of modern information and communication technologies. More specifically, we carried out a pilot project [46] and an evaluative study with a pretest/posttest design [47] in order to determine whether this same program could be delivered via web mode or "online" and to assess its effects on the same health indicators.

Our online stress management program comprises seven 60- to 90-minute sessions to be completed one per week at the caregiver's convenience. Each session comprises specific individual objectives and learning activities in the form of exercises that correspond to the principal steps of the stress management process. Healthcare professionals play the role of online coach. They offer a tutorial, help participants complete the activities, and are available to answer questions three times a week during preestablished time slots. The program allows caregivers to work individually while giving them the opportunity to interact with other caregivers online on a discussion forum. As the practitioner (coach) is not always present on the web and as caregivers have many individual tasks to perform, the content of the e-program is spread over a longer period of time ( 7 sessions) than is the face-to-face stress management program (6 sessions) in order to assure a certain degree of intensity.

For the purposes of evaluating this online program, caregivers were recruited via a website intended for family caregivers and filled out their consent forms and the evaluation questionnaires online. A total of 26 caregivers participated in the pilot quantitative evaluation of this on-line program. The e-learning intervention had statistically significant effects on QoL indicators similar to those observed in our evaluation of the program offered in face-to-face mode. More specifically, the results of nonparametric analyses (Wilcoxon test) performed using the scores on the same measuring instruments as those in the evaluation of the individual face-to-face program demonstrated that caregivers perceived greater control over their caregiving situation $(p=.04)$, considered their caregiver role as less of a threat $(p=.04)$ and more of a challenge $(p=.05)$, and felt greater self-efficacy regarding their ability to ask for help, if needed, from their social networks, both informal (family and friends) and formal (services) $(p=.01)$. 
These results underscore the potential of this innovative intervention approach in the light of the rapid spread of internet use among people of all ages and of the isolation of family caregivers. Accessibility and asynchronism are the main advantages afforded by this online training program. The results obtained to date suggest that this approach to learning stress management holds great promise. A largerscale study is presently underway.

In conclusion, this program offered in two modes of intervention allows meeting the specific needs of caregivers in the middle of what Pearlin and colleagues [48] called their caregiver "career," a period littered with stressors with which they must deal on a daily basis.

The following section summarizes how a group program for family caregivers of an institutionalized relative was developed through participatory action research, how it was evaluated, and the results of its empirical evaluation. The program titled taking care of myself offers an educational and support intervention for another stage of the caregiver career, when home care is no longer possible.

\section{When Placement in Long-Term Care Is Inevitable: The Taking Care of Myself Program}

4.1. Background of Study and Program's Coconstruction Process. In North America, as in several European countries, elderly persons afflicted by dementia make up the vast majority of the institutionalized clientele in long-term care settings (e.g., nursing homes and long-stay hospitals). Under the caregiving career framework developed by Montgomery and Kolosky [49] to understand variations in the caregiving experience, institutionalization is considered another key marker of the caregiving trajectory. Many family caregivers who reach this stage resort to long-term placement when their health and that of their relative have deteriorated severely [50]. However, despite the importance of institutionalization as a milestone in the caregiving career, much less research has focused on these caregivers compared to those who care for an elderly relative at home, in the belief that institutionalization diminishes, ipso facto, their psychological exhaustion [51]. Yet, certain studies [52, 53] have demonstrated that family caregivers of an institutionalized elderly relative constitute an at-risk group in terms of mental health on a par with caregivers of a relative living at home. Furthermore, as support from family and friends decreases after the relative's placement, the isolation and burden of caregivers tend to increase [54]. That said, little is known about the health needs of family caregivers of an institutionalized elderly relative with dementia and the stressful situations that they face. This knowledge is essential in order to develop interventions tailored to the needs of family caregivers at this specific juncture of their caregiving career.

These observations led us to undertake a four-stage study [55] based on a participatory action research model where family caregivers were considered experts and coresearchers playing an active role in every step of the research process.
At the first stage, results from six focus groups revealed that these caregivers were exposed to several stressful situations, including the grief of witnessing a relative's deterioration, difficulty communicating with the relative, and lack of support from family, friends, and healthcare staff. Other stressors specific to the institutional setting were related to the under consideration of families in the decisions concerning their relative's care, the lack of control by caregivers over quality of care, and the lack of ease expressing their viewpoints to healthcare staff.

In the second stage of the research project, 11 workshops were organized with family caregivers who had taken part in the focus groups, in the aim of developing an intervention program comprising elements that would enable them to acquire skills for dealing with stressors and, in turn, greater control over caregiving situations. The third stage consisted in testing the program on a group of six family caregivers who had not taken part in the workshops and in evaluating it qualitatively (for details on the development process, see [55]). Thereafter, a multisite randomized study was conducted, the purpose of which was to test both the efficacy of the intervention program to enhance family caregiver QoL [56] and its persistent effects [57].

4.2. Theoretical Framework. An important point reported by families in the first stage of our study had to do with the little control they had over the quality of care received by their relatives. This lack of control stemmed from being considered mere spectators of care rather than expert caregivers [55]. Perceived control appears to have a unique effect on mental health in family caregivers. Pearlin et al. [48] reported that the level of control people believing they could exercise over certain aspects of a situation was a major factor in mental health. Another study [58] indicated that the higher the level of perceived control in family caregivers is, the less they were at risk of suffering from psychological distress when the degree of perceived stress was controlled. Considering these empirical data and considering our own results, our main objectives were to enable caregivers to acquire both greater control over caregiving situations and skills for dealing with stressors. Consequently, the development of the intervention program was based on a perspective of empowerment, globally defined as a process by which a sense of being able to exercise greater control through concrete actions is developed [59], and on the theoretical model of stress and coping [44].

4.3. Description of Intervention Program. As mentioned earlier, the taking care of myself program was coconstructed with family caregivers. It is a psychoeducational group program focused on (1) cognitive appraisal of stressors; (2) empowerment of family caregivers through a heightened awareness of their strengths and their capacity to change their perception of stress and exercise control over their environment; and (3) utilization of three coping strategies for dealing with stressful situations: problem solving, reframing, and stress symptoms management.

The program consists of ten 90-minute weekly sessions for groups of six to eight family caregivers. It covers the following six themes: (1) how to feel at ease with my relative; 
TABLE 3: Objectives and content summary of taking care of myself program for family caregivers of an institutionalized aging relative suffering from dementia.

\begin{tabular}{|c|c|c|}
\hline Topic of meetings & Specific objectives & Content \\
\hline $\begin{array}{l}\text { Session } 1 . \text { Getting to know } \\
\text { one another }\end{array}$ & $\begin{array}{l}\text { (i) Introduce participants to objectives, content, and } \\
\text { course of program } \\
\text { (ii) Allow participants to share caregiver experience in } \\
\text { nursing home settings relative to their health }\end{array}$ & $\begin{array}{l}\text { (i) Participants' expectations } \\
\text { (ii) Presentation of program } \\
\text { (iii) Exchanges among caregivers }\end{array}$ \\
\hline $\begin{array}{l}\text { Session } 2 \text {. How to feel good } \\
\text { with your relative }\end{array}$ & $\begin{array}{l}\text { Improve caregivers' perceived competence in } \\
\text { interactions with relatives }\end{array}$ & $\begin{array}{l}\text { Impact of illness on relative's behaviour: } \\
\text { perception of sources of stress; ways of } \\
\text { improving communication }\end{array}$ \\
\hline $\begin{array}{l}\text { Sessions } 3 \text { and } 4 \text {. How to } \\
\text { communicate your point of } \\
\text { view to staff }\end{array}$ & $\begin{array}{l}\text { Improve caregivers' ability to express opinions } \\
\text { regarding care provided relatives and to take part in } \\
\text { decisions concerning them }\end{array}$ & $\begin{array}{l}\text { (i) Relations with staff } \\
\text { (ii) Problem solving } \\
\text { (iii) Empowerment } \\
\text { (iv) Rights of family members } \\
\text { (v) Complaint-handling procedure }\end{array}$ \\
\hline $\begin{array}{l}\text { Sessions } 5 \text { and } 6 . \text { How to } \\
\text { avoid emotional turmoil }\end{array}$ & $\begin{array}{l}\text { Enable caregivers to appraise caregiving experience } \\
\text { differently and to cope with difficult emotions }\end{array}$ & $\begin{array}{l}\text { Thought-modification strategy (e.g., } \\
\text { reframing a difficult situation) }\end{array}$ \\
\hline $\begin{array}{l}\text { Sessions } 7 \text { and } 8 \text {. How to } \\
\text { deal with small losses on a } \\
\text { daily basis and prepare for } \\
\text { the eventual loss of your } \\
\text { relative }\end{array}$ & $\begin{array}{l}\text { (i) Facilitate awareness of many losses caused by } \\
\text { relative's illness and improve caregiver ability to cope } \\
\text { with these losses } \\
\text { (ii) Enable caregivers to cope with eventual loss of } \\
\text { relative }\end{array}$ & $\begin{array}{l}\text { (i) Losses caused by illness } \\
\text { (ii) Grieving process } \\
\text { (iii) Strategies for dealing with losses and } \\
\text { grieving: thought modification } \\
\text { (iv) Preparing for eventual loss of relative }\end{array}$ \\
\hline $\begin{array}{l}\text { Session } 9 . \text { How to } \\
\text { reorganize your life after } \\
\text { placement of your relative }\end{array}$ & $\begin{array}{l}\text { Increase caregiver self-confidence in ability to } \\
\text { reorganize life and to take care of themselves }\end{array}$ & $\begin{array}{l}\text { (i) Reorganizing one's life } \\
\text { (ii) Strategies for taking care of oneself }\end{array}$ \\
\hline $\begin{array}{l}\text { Session } 10 . \text { How to identify } \\
\text { and call on your support } \\
\text { network }\end{array}$ & $\begin{array}{l}\text { Increase caregiver ability to call on support network to } \\
\text { meet own needs }\end{array}$ & How to ask for support \\
\hline
\end{tabular}

(2) how to express my point of view to healthcare staff; (3) how to avoid emotional turmoil; (4) how to deal with small daily losses and be prepared for the ultimate loss of my relative; (5) how to identify and call upon my family support network and community services; and (6) how to reorganize my life after my relative's institutionalization and take care of myself (see [55]). A participatory approach is used (e.g., discussions, written exercises between sessions, and role playing), centred on the actual concerns of family caregivers in order to foster transfer of the strategies learned. Table 3 presents the elements of the program.

4.4. Program Effects on Selected QoL Outcomes . As previously mentioned, we tested the efficacy of this program on selected indicators of family caregiver QoL $[56,57]$. Three groups of caregivers were compared. One took part in the experimental intervention program $(n=45)$ and one in a comparison program offered by the Quebec Alzheimer Society $(n=51)$; the third was a control group $(n=41)$. Prediction data analyses showed two "successful" outcomes to be unique to our program, that is, competence dealing with healthcare staff $(z=1.96, p=.05)$ and perceived challenge of caregiver role (e.g., motivation to find solutions on account of the caregiver role; $z=2.07, p=.05$ ). It is not unreasonable to think that the frame of reference underlying this program (i.e., a general empowerment approach), which is complementary to the stress and coping theory, is one explanation for these effects. Also, predicted effects were noted in proportionally more EG caregivers (71.1\% versus
$50.1 \%$ ) on the following variables: self-control, perceived formal and informal support, role overload, and use of the coping strategy of reframing.

We also tested the persistent and delayed effects of the program three months later using prediction analyses. Results reveal that competence dealing with healthcare staff and use of the coping strategy of reframing were persistent effects unique to the experimental group and that perceived formal and informal support was a persistent effect in both the experimental group and in the comparison group (for details see [57]). These results underscore the importance of carrying out follow-up assessments of psychoeducational intervention programs in order to determine whether their effects persist over time.

In conclusion, this multistage study demonstrated once again that caregivers have specific needs at different moments along the caregiving trajectory and that intervention programs offered have to be designed to fit these needs. The taking care of myself program is a program tailored to caregivers of institutionalized persons living with dementia.

\section{Discussion and Future Directions for Caregiving Research on Interventions}

The utilitarian approach currently prevailing within the healthcare system in the context of the aging of the population-an approach geared towards maintaining the functional autonomy of aging persons [60]—often neglects to 
take into account the needs of the family. As our research program is intended for family caregivers, a paradigm shift is called for. Caregiving families must no longer be viewed solely as resources by the healthcare system. Rather, they must be looked upon as clients. The urgent need to take into consideration the health of family caregivers is being increasingly recognized as a public health issue [61, 62]. Furthermore, carrying out interventions in a timely fashion allows the temporal dimension of the caregiver career to be taken into account. In this regard, it has been recommended for almost two decades that the timing and content of intervention programs are modulated as a function of the different stages of the caregiver career, given that the process of adapting to a new situation occurs within a specific context [18]. Our program is consistent with this recommendation.

Our five-step approach to develop a proactive psychoeducational intervention for family caregivers following disclosure of a relative's diagnosis (i.e., the learning to become a family caregiver program) is an example of a tailored intervention and is characterized by several innovations. First, it falls within the sphere of proactive interventions, with a view to preparing family caregivers from the outset of the caregiving trajectory to deal with what lies ahead. Early intervention is called for given that, as fatigue and psychological distress mount, caregivers reportedly have a much harder time putting into practice the strategies proposed in intervention programs [63]. The theoretical model of role transitions developed by Meleis et al. [26], which was chosen to provide the underpinning for the development of our program, fits in with the notion of the temporality of the caregiver career.

The other two programs presented in this paper (i.e., the stress management program and the taking care of myself program) also illustrate the importance of taking into account the specific needs of caregivers at different moments of the caregiver career. Interventions must be designed and offered as a function of this specificity as their effects on QoL will differ. This underscores the fact that "one size fits all" should not be the rule for caregiver support.

It is important to acknowledge, also, that until now most researchers have developed programs without family caregiver participation. This observation led certain authors to recommend emphatically that efforts should be made to establish a dialogue with these caregivers with a view to tailoring intervention programs to their needs $[10,64]$. From this point of view, our research program is innovative in the participatory and constructivist approach employed. Accordingly, family caregivers were considered the principal stakeholders in the matter and, as such, were the ones to identify the content to be covered in order to render programs sensitive to their needs. Research conducted with family caregivers $[10,23]$ has highlighted the relevance of developing the content of intervention programs in partnership with the key actors concerned, as such a strategy is more likely to motivate potential participants in the future. Further, as mentioned by Denis and Lomas [65], a study is useful only to the extent that it reflects the values and interests of the interested parties. Based on a pragmatic epistemology, this type of participation contributes to ensure a program's ecological validity [65]. Though essential in principle, this has, in practice, seldom been incorporated in the program development process [28].

The results of our evaluative studies using mixed research designs provide evidence for guiding clinical practice. Healthcare staff still have few tested interventions at their disposal.

However, it is important to point out the limitations of our research in the field of caregiving. Though our work has made it possible to develop innovative interventions allowing professionals to take into account the needs of family caregivers and their context, it did not explicitly consider family dynamics on the whole or even a systemic perspective. The complexity of family interactions and the limitations inherent in the research process, particularly with regard to quantitative explicative studies, explain in part the choices that we made. All the same, as recommended by certain authors in the field of caregiving [10], future studies that will be carried out as part of our research program will inevitably need to consider the caregiver/care-recipient dyad and the interactions that occur within this important family subsystem. Moreover, it will be imperative to explore and consider the viewpoint of other family members who-and this is something we acknowledge-are greatly engaged in and affected by the process of care for one of their own suffering from a health problem.

In conclusion, at a time when health care budgets are being cut everywhere in the western world, family caregivers are considered much more as coworkers or resources to be used in caring for their elderly relatives than from a more systemic perspective as potential clients in their right of the healthcare system. If we wish to avoid the heavy health consequences that long-term caregiving engenders, these family caregivers warrant that attention should be paid to their needs by health and social policies. As mentioned by Choi and colleagues [66] a decade ago, research informing policymakers is important, not to mention that it is urgent that intervention research for caregivers is prioritized and taken into account in future policymaking.

\section{Conflict of Interests}

The author declares that there is no conflict of interests regarding the publication of this paper.

\section{References}

[1] M. Lopez-Hartmann, J. Wens, V. Verhoeven, and R. Remmen, "The effect of caregiver support interventions for informal caregivers of community-dwelling frail elderly: a systematic review," International Journal of Integrated Care, vol. 12, no. 20, article el33, 2012.

[2] R. Schulz and L. Martire, "Family caregiving of persons with dementia: prevalence, health effects, and support strategies," The American Journal of Geriatric Psychiatry, vol. 12, pp. 240 249, 2004.

[3] H. Brodaty, A. Green, and A. Koschera, "Meta-analysis of psychosocial interventions for caregivers of people with dementia," Journal of the American Geriatrics Society, vol. 51, no. 5, pp. 657664, 2003. 
[4] D. D. Cooke, L. McNally, K. T. Mulligan, M. J. G. Harrison, and S. P. Newman, "Psychosocialinterventions for caregivers of people with dementia: a systematic review," Aging and Mental Health, vol. 5, no. 2, pp. 120-135, 2001.

[5] Haute Autorité de Santé, Synthesis of Best Practice Recommendations: Alzheimer and Related Diseases, Author, Paris, France, 2010.

[6] M. S. Mittelman, H. Brodaty, A. S. Wallen, and A. Burns, "A three-country randomized controlled trial of a psychosocial intervention for caregivers combined with pharmacological treatment for patients with alzheimer disease: effects on caregiver depression," The American Journal of Geriatric Psychiatry, vol. 16, no. 11, pp. 893-904, 2008.

[7] H. Pusey and D. Richards, "A systematic review of the effectiveness of psychosocial interventions for carers of people with dementia," Aging and Mental Health, vol. 5, no. 2, pp. 107-119, 2001.

[8] S. Sörensen, M. Pinquart, and P. Duberstein, "How effective are interventions with caregivers? An updated meta-analysis," Gerontologist, vol. 42, no. 3, pp. 356-372, 2002.

[9] C. A. Thompson, K. Spilsbury, J. Hall, Y. Birks, C. Barnes, and J. Adamson, "Systematic review of information and support interventions for caregivers of people with dementia," $B M C$ Geriatrics, vol. 7, article 18, 2007.

[10] S. H. Zarit and E. E. Femia, "A future for family care and dementia intervention research? Challenges and strategies," Aging and Mental Health, vol. 12, no. 1, pp. 5-13, 2008.

[11] S. H. Zarit and S. A. Leitsch, "Developing and evaluating community based intervention programs for Alzheimer's patients and their caregivers," Aging and Mental Health, vol. 5, supplement 1, pp. S84-S98, 2001.

[12] F. Ducharme, L. Beaudet, J. Ward, and A. Legault, Learning to Become a Caregiver!" Psychoeducational Program for Caregivers of an Elderly Relative Recently Diagnosed with Alzheimer's Disease, Desjardins Research Chair in Nursing Care for Seniors and Their Families, Research Centre, Institut Universitaire de Gériatrie de Montréal, Montreal, Canada, 2012.

[13] F. Ducharme, D. Trudeau, and J. Ward, Stress Management Psychoeducational Program for Caregivers of an Elderly Relative at Home, Desjardins Research Chair in Nursing Care for Seniors and Their Families, Research Centre, Institut Universitaire de Gériatrie de Montréal, Montreal, Canada, 2013.

[14] F. Ducharme, L. Lévesque, M. Gendron, A. Legault, D. Trudeau, and J. Ward, Taking Care of Myself. An Intervention Program for Families of Seniors in Nursing Homes, Desjardins Research Chair in Nursing Care for Seniors and Their Families, Research Centre, Institut Universitaire de Gériatrie de Montréal, Montreal, Canada, 2010.

[15] M. Pinquart and S. Sörensen, "Helping caregivers of persons with dementia: which interventions work and how large are their effects?" International Psychogeriatrics, vol. 18, no. 4, pp. 577-595, 2006.

[16] M. Nolan, T. Ryan, P. Enderby, and D. Reid, "Towards a more inclusive vision of dementia care practice and research," Dementia, vol. 1, no. 2, pp. 193-211, 2002.

[17] H. Brodaty, M. Gresham, and G. Luscome, "The Prince Henry Hospital dementia caregivers' training programme," International Journal of Geriatric Psychiatry, vol. 12, no. 2, pp. 183-192, 1997.

[18] C. Aneshensel, L. Pearlin, J. Mullan, S. Zarit, and C. Whitlatch, Profiles in Caregiving: The Unexpected Career, Academic Press, San Diego, Calif, USA, 1995.
[19] J. Keady and M. Nolan, "The dynamics of dementia: working together, working separately, or working alone?” in Partnerships in Family Care, M. Nolan, U. Lundh, G. Grant, and J. Keady, Eds., pp. 15-32, Open University Press, Philadelphia, Pa, USA, 2003.

[20] D. R. Kuhn, "Caring for relatives with early stage Alzheimer's disease: an exploratory study," The American Journal of Alzheimer's Disease and other Dementias, vol. 13, no. 4, pp. 189196, 1998.

[21] C. Wald, M. Fahy, Z. Walker, and G. Livingston, "What to tell dementia caregivers-the rule of threes," International Journal of Geriatric Psychiatry, vol. 18, no. 4, pp. 313-317, 2003.

[22] C. L. Lindgren, “The caregiver career," Image, vol. 25, no. 3, pp. 214-219, 1993.

[23] F. Ducharme, L. Beaudet, A. Legault, M.-J. Kergoat, L. Lévesque, and C. Caron, "Development of an intervention program for Alzheimer's family caregivers following diagnostic disclosure," Clinical Nursing Research, vol. 18, no. 1, pp. 44-67, 2009.

[24] F. C. Ducharme, L. L. Lévesque, L. M. Lachance et al., "Learning to become a family caregiver efficacy of an intervention program for caregivers following diagnosis of dementia in a relative," Gerontologist, vol. 51, no. 4, pp. 484-494, 2011.

[25] F. Ducharme, L. Lachance, L. Lévesque, S. Zarit, and M. J. Kergoat, "Maintaining the potential of a psychoeducational program: efficacy of a booster session after an intervention offered family caregivers at disclosure of a relative's dementia diagnosis," Aging and Mental Health. In press.

[26] A. I. Meleis, L. M. Sawyer, E.-O. Im, D. K. H. Messias, and K. Schumacher, "Experiencing transitions: an emerging middlerange theory," Advances in Nursing Science, vol. 23, no. 1, pp. $12-28,2000$.

[27] E. Guba and Y. Lincoln, Fourth Generation Evaluation, Sage, Newbury Park, Calif, USA, 1989.

[28] K. Bartholomew, G. Parcel, G. Kok, N. Gottlieb, and M. Fernandez, Planning Health Promotion Programs: An Intervention Mapping Approach, John Wiley and Sons, San Francisco, Calif, USA, 2011.

[29] C. Clark, D. Chaston, and G. Grant, "Early interventions in dementia: carer-led evaluations," in Partnerships in Family Care, M. Nolan, U. Lundh, G. Grant, and J. Keady, Eds., pp. 33-49, Open University Press, Philadelphia, Pa, USA, 2003.

[30] L. West, Early Stage Dementia, Newleaf, Taunton, UK, 2nd edition, 2001.

[31] S. H. Zarit, E. E. Femia, J. Watson, L. Rice-Oeschger, and B. Kakos, "Memory club: a group intervention for people with early-stage dementia and their care partners," Gerontologist, vol. 44 , no. 2, pp. 262-269, 2004.

[32] R. Whittemore and M. Grey, "The systematic development of nursing interventions," Journal of Nursing Scholarship, vol. 34, no. 2, pp. 115-120, 2002.

[33] S. Kemmis and R. McTaggart, "Participatory action research," in Handbook of Qualitative Research, N. Denzin and Y. Lincoln, Eds., pp. 567-605, Sage, Toronto, Canada, 2000.

[34] L. M. . Wright, W. L. Watson, and J. M. Bell, Beliefs: the Heart of Healing in Families and Illness, Basic Book, New York, NY, USA, 1996.

[35] A. Bandura, Self-Efficacy: The Exercise of Control, Freeman, New York, NY, USA, 1997.

[36] A. Bandura, Self-Efficacy: The Sense of Personal Competence, de Boeck, Paris, France, 2003. 
[37] A. M. Zeiss, D. Gallagher-Thompson, S. Lovett, J. Rose, and C. McKibbin, "Self-efficacy as a mediator of caregiver coping: development and testing of an assessment model," Journal of Clinical Geropsychology, vol. 5, no. 3, pp. 221-230, 1999.

[38] D. . Hildebrand, J. Laing, and H. Rosenthal, Prediction Analysis of Cross-Classifications, Wiley, New York, NY, USA, 1977.

[39] C. J. Whitlatch, S. H. Zarit, and A. von Eye, "Efficacy of interventions with caregivers: a reanalysis," Gerontologist, vol. 31, no. 1, pp. 9-14, 1991.

[40] M. A. Whisman, "The efficacy of booster maintenance sessions in behavior therapy: review and methodological critique," Clinical Psychology Review, vol. 10, no. 2, pp. 155-170, 1990.

[41] P. Stoltz, G. Udén, and A. Willman, "Support for family carers who care for an elderly person at home-a systematic literature review," Scandinavian Journal of Caring Sciences, vol. 18, no. 2, pp. 111-119, 2004.

[42] F. Ducharme, G. Pérodeau, and D. Trudeau, "Perceptions, coping strategies and expectations of elderly female natural caregivers within the context of the shift to ambulatory care," Canadian Journal of Community Mental Health, vol. 19, no. 1, pp. 79-103, 2000.

[43] F. Ducharme, P. Lebel, L. Lachance, and D. Trudeau, "Implementation and effects of an individual stress management intervention for family caregivers of an elderly relative living at home: a mixed research design," Research in Nursing and Health, vol. 29, no. 5, pp. 427-441, 2006.

[44] R. Lazarus and S. Folkman, Stress, Appraisal, and Coping, Springer, New York, NY, USA, 1984.

[45] K. Rockwood, "Integration of research methods and outcome measures: comprehensive care for the frail elderly," Canadian Journal on Aging, vol. 14, supplement 1, pp. 151-164, 1995.

[46] F. Ducharme, D. Trudeau, C. Rowan, S. Savard, and P. Lebel, "Helping family caregivers manage their stress through online training: is it possible?" Counselling and Spirituality, vol. 28, no. 1, pp. 33-53, 2009.

[47] F. Ducharme, V. Dubé, L. Lévesque, D. Saulnier, and F. Giroux, "An online stress management training program as a supportive nursing intervention for family caregivers of an elderly person," Canadian Journal of Nursing Informatics, vol. 6, no. 2, 2011, http://cjni.net/journal/?p=1344 .

[48] L. I. Pearlin, J. T. Mullan, S. J. Semple, and M. M. Skaff, "Caregiving and the stress process: an overview of concepts and their measures," Gerontologist, vol. 30, no. 5, pp. 583-594, 1990.

[49] R. J. V. Montgomery and K. D. Kolosky, "Family caregiving: change, continuity, and diversity," in InInterventions in Dementia Care: Toward Improving Quality of Life, M. P. Lawton and R. L. Rubinstein, Eds., pp. 143-171, Springer, New York, NY, USA, 2000.

[50] M. C. Chenier, "Review and analysis of caregiver burden and nursing home placement: the multiple problems and variables affecting the caregiving relationships require multiple approaches and interventions," Geriatric Nursing, vol. 18, no. 3, pp. 121-126, 1997.

[51] M. J. Naleppa, "Families and the institutionalized elderly: a review," Journal of Gerontological Social Work, vol. 27, pp. 87$111,1996$.

[52] K. Hooker, S. R. Bowman, D. P. Coehlo et al., "Behavioral change in persons with dementia: relationships with mental and physical health of caregivers," Journals of Gerontology B: Psychological Sciences and Social Sciences, vol. 57, no. 5, pp. P453-P460, 2002.
[53] B. J. Kramer, "Husbands caring for wives with dementia: a longitudinal study of continuity and change," Health and Social Work, vol. 25, no. 2, pp. 97-107, 2000.

[54] P. McCallion, R. W. Toseland, and K. Freeman, "An evaluation of a family visit education program," Journal of the American Geriatrics Society, vol. 47, no. 2, pp. 203-214, 1999.

[55] F. Ducharme, L. Lévesque, M. Gendron, and A. Legault, "A program to promote the mental health of family caregivers of elderly demented parents in institution: Qualitative evaluation," Clinical Nursing Research, vol. 10, no. 1, pp. 182-201, 2001.

[56] F. Ducharme, L. Lévesque, L. Lachance, A. Legault, and M. Préville, "Taking care of myself: efficacy of an intervention program for caregivers of a relative suffering from dementia living in a long-term care setting," Dementia, vol. 4, no. 1, pp. 23-47, 2005.

[57] F. Ducharme, L. Lévesque, F. Giroux, and L. Lachance, "Followup of an intervention program for caregivers of a relative with dementia living in a long-term care setting: are there any persistent and delayed effects?" Aging and Mental Health, vol. 9, no. 5, pp. 461-469, 2005.

[58] M. E. Yates, S. Tennstedt, and B.-H. Chang, "Contributors to and mediators of psychological well-being for informal caregivers," Journals of Gerontology B: Psychological Sciences and Social Sciences, vol. 54, no. 1, pp. P12-P22, 1999.

[59] M. A. Zimmerman, "Psychological empowerment: issues and illustrations," The American Journal of Community Psychology, vol. 23, no. 5, pp. 581-599, 1995.

[60] F. Béland and A. Lemay, "Dilemmas and values for a long-term services policy," Canadian Journal on Aging, vol. 14, pp. 263-293, 1995.

[61] Canadian Caregiver Coalition, "Framework for a caregiving strategy," 2005, http://www.ccc-ccan.ca/ .

[62] National Family Caregivers Association, Caregivers Survey, 2000, National Family Caregivers Association, Kensington, Md, USA, 2000.

[63] M. Nolan, G. Grant, and J. Keady, Understanding Family Care: A Multidimensional Model of Caring and Coping, Open University Press, Buckingham, UK, 1996.

[64] B. van Meijel, C. Gamel, B. van Swieten-Duijfjes, and M. H. F. Grypdonck, "The development of evidence-based nursing interventions: methodological considerations," Journal of Advanced Nursing, vol. 48, no. 1, pp. 84-92, 2004.

[65] J.-L. Denis and J. Lomas, "Convergent evolution: the academic and policy roots of collaborative research," Journal of Health Services Research and Policy, vol. 8, supplement 2, pp. 1-6, 2003.

[66] B. C. K. Choi, T. Pang, V. Lin et al., "Can scientists and policy makers work together?" Journal of Epidemiology and Community Health, vol. 59, no. 8, pp. 632-637, 2005.

[67] S. Folkman, M. Chesney, L. McKusick, G. Ironson, D. Johnson, and T. Coates, "Translating coping theory into an intervention," in The Social Context of Coping, J. Eckenrode, Ed., pp. 239-260, Plenum Press, New York, NY, USA, 1991.

[68] T. Kitwood, Dementia Reconsidered: The Person Comes First, Open University Press, Buckingham, UK, 1997.

[69] D. Gauvreau and S. Gendron, Questions et Réponses sur la Maladie d'Alzheimer, Le Jour, Montréal, Canada, 1994.

[70] K. L. Schumacher, B. J. Stewart, P. G. Archbold, M. J. Dodd, and S. L. Dibble, "Family caregiving skill: development of the concept," Research in Nursing and Health, vol. 23, no. 3, pp. 191203, 2000. 
[71] N. Carpentier and F. Ducharme, "Support network transformations in the first stages of the caregiver's career," Qualitative Health Research, vol. 15, no. 3, pp. 289-311, 2005.

[72] B. Trelaun, Conflits dans la Famille: Manuel pour Sortir des Querelles, Chronique Sociale, Lyon, France, 2003. 


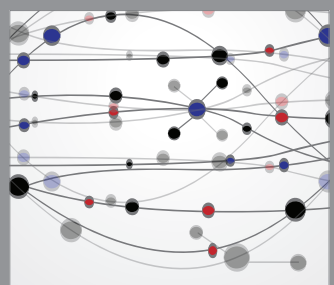

The Scientific World Journal
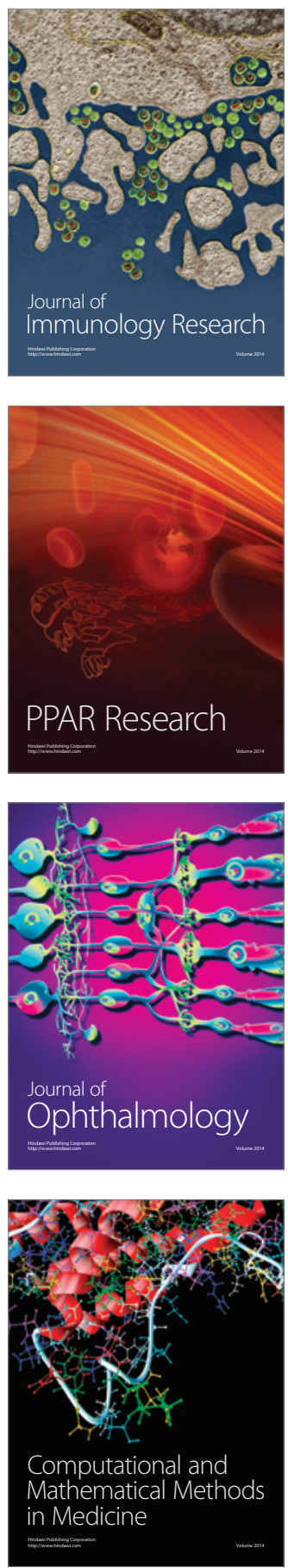

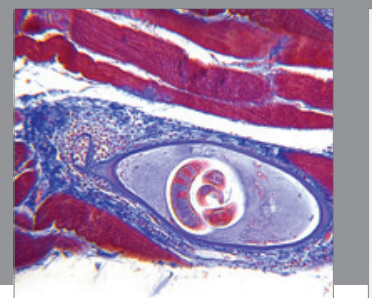

Gastroenterology

Research and Practice
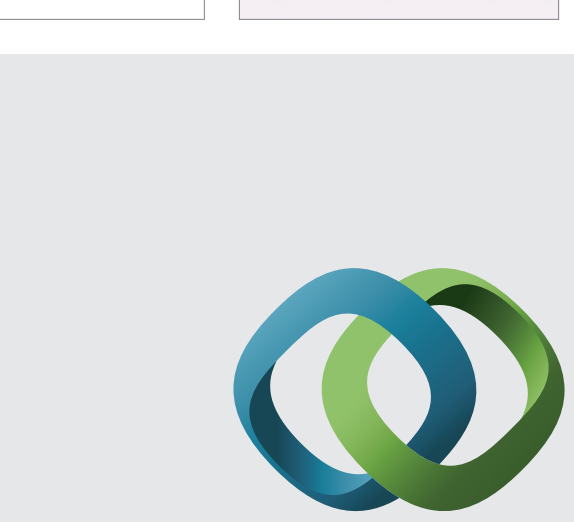

\section{Hindawi}

Submit your manuscripts at

http://www.hindawi.com
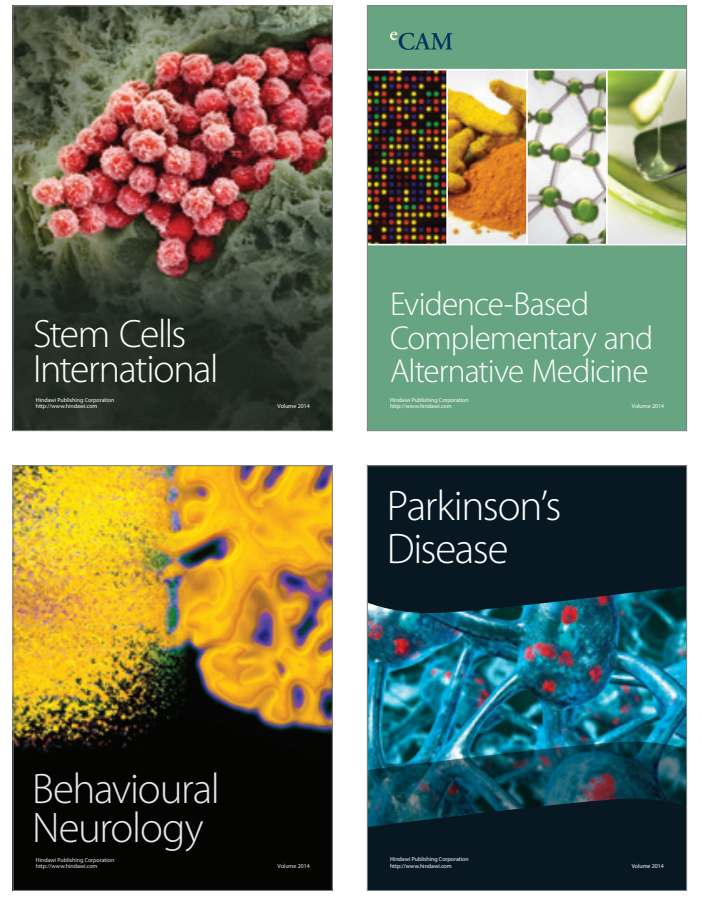
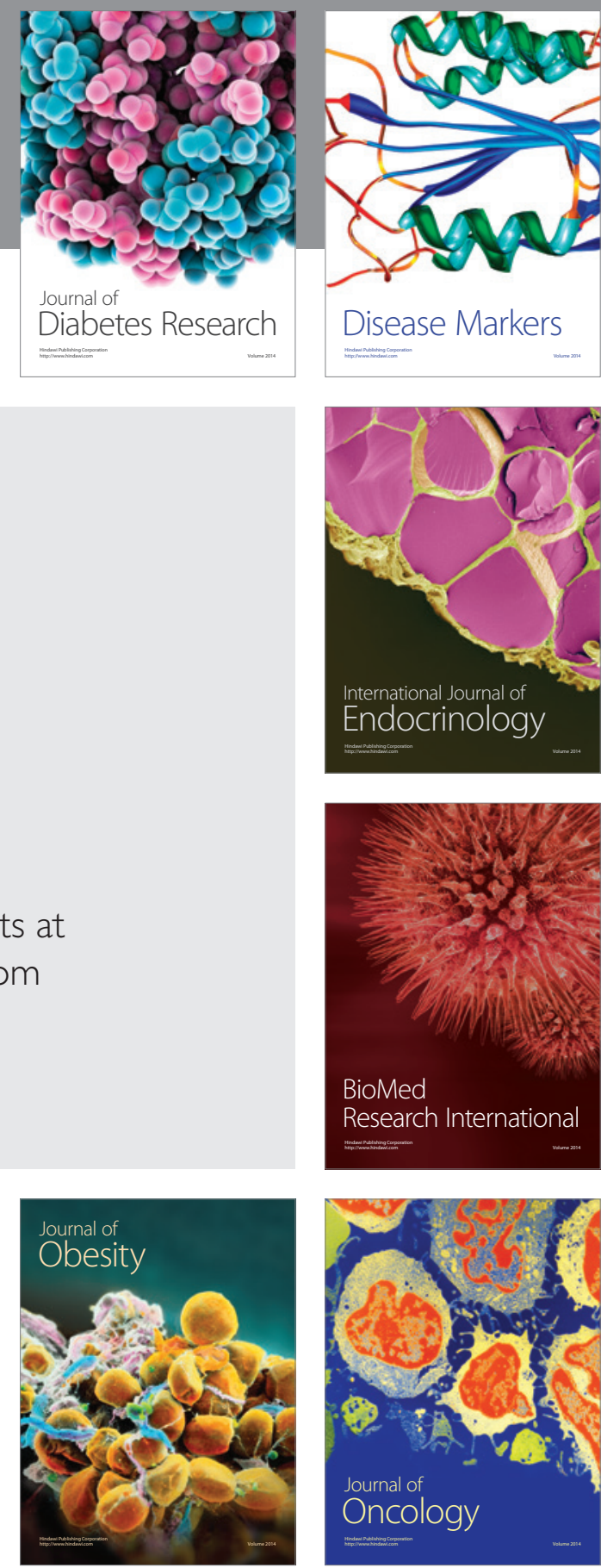

Disease Markers
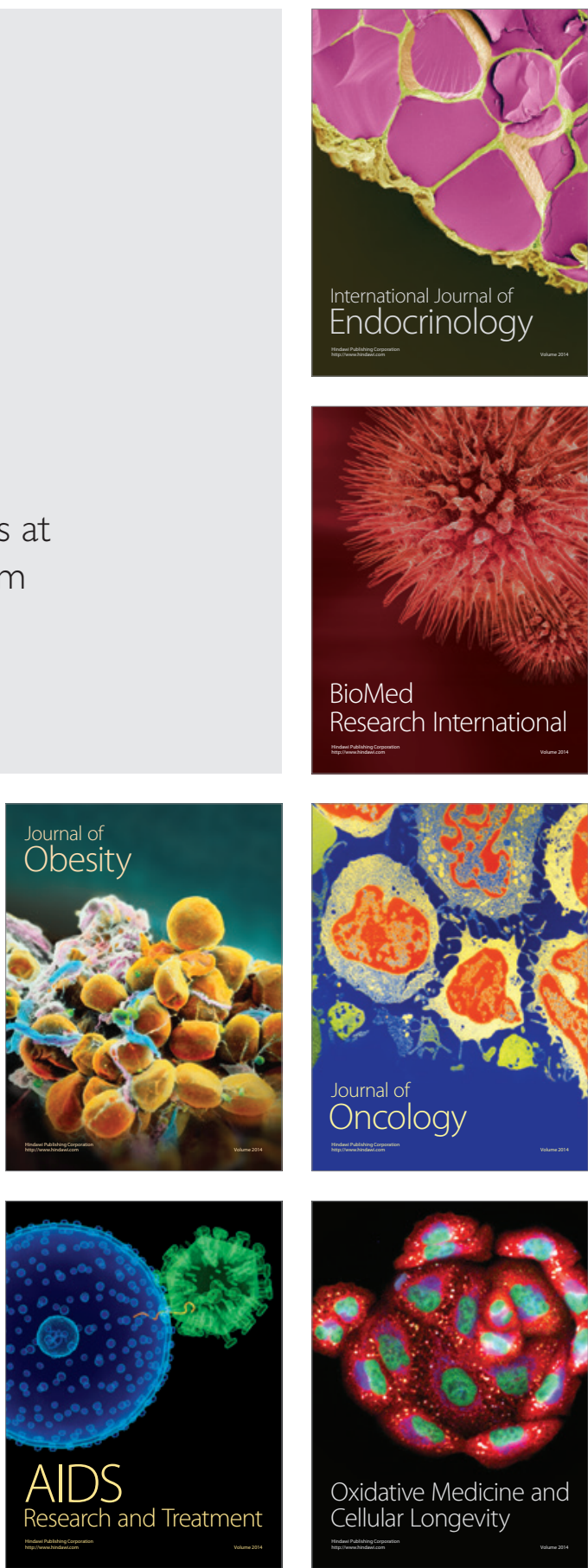